\title{
The nurse's work environment in a hospital emergency service
}

\author{
Ambiente de trabalho do enfermeiro em um serviço hospitalar de emergência
}

José Luís Guedes dos Santos ${ }^{1}$, Fernando Henrique Antunes Menegon ${ }^{1}$, Shara Bianca De Pin ${ }^{1}$, Alacoque Lorenzini Erdmann ${ }^{1}$, Roberta Juliane Tono de Oliveira ${ }^{1}$, Inácio Alberto Pereira Costa ${ }^{1,2}$

Objective: to analyze the characteristics of the nurse's work environment in a hospital emergency service. Methods: a mixed method study with a concurrent triangulation strategy using data from a descriptiveexploratory study, with 19 nurses, and a Grounded Theory study with three sample groups totaling 21 participants. The quantitative data were collected using the Brazilian Nursing Work Index - Revised and were subjected to descriptive statistical analysis. The qualitative data were obtained from interviews and were analyzed through initial and focused coding. Results: the nurses considered that they had autonomy, good relationships with the physicians, and organizational support. However, the control over the environment was shown to be an unfavorable characteristic. Based on the results, the category: "Seeking to organize the work environment for demand which exceeds attendance capacity" is presented. Conclusion: the characteristics of the emergency environment were shown to be favorable to the nurse's work, with the exception of control over the environment.

Descriptors: Working Environment; Nursing Care; Management; Emergency Nursing.

Objetivo: analisar as características do ambiente de trabalho do enfermeiro em um serviço hospitalar de emergência. Métodos: estudo de método misto com estratégia triangulação concomitante de dados de um estudo descrito-exploratório com 19 enfermeiros e uma Teoria Fundamentada nos Dados com três grupos amostrais, perfazendo 21 participantes. Os dados quantitativos foram coletados por meio do Brazilian Nursing Work Index Revised e submetidos à análise estatística descritiva. Os dados qualitativos foram obtidos a partir de entrevistas e analisados mediante codificação inicial e focalizada. Resultados: os enfermeiros consideraram ter autonomia, boas relações com os médicos e suporte organizacional. No entanto, o controle sobre o ambiente mostrou-se como característica desfavorável. A partir dos resultados, apresenta-se a categoria: "Buscando organizar o ambiente de trabalho para uma demanda maior do que a capacidade de atendimento". Conclusão: as características do ambiente da emergência mostraram-se favoráveis ao trabalho do enfermeiro, exceto o controle sobre o ambiente.

Descritores: Ambiente de Trabalho; Cuidados de Enfermagem; Gerência; Enfermagem em Emergência.

\footnotetext{
${ }^{1}$ Universidade Federal de Santa Catarina. Florianópolis, SC, Brazil.

${ }^{2}$ Instituto Federal de Santa Catarina. Florianópolis, SC, Brazil. 


\section{Introduction}

The nurse's work is influenced by the characteristics of the health service in which she undertakes her professional practice. Among these characteristics, emphasis is placed upon: the size of the organization, professional hierarchies, infrastructure conditions, social norms and policies for appropriate behaviour ${ }^{(1)}$. Depending on these specific characteristics, the work environment may facilitate or restrict the nurse's practice, mainly regarding the nurse's leadership and autonomy ${ }^{(2)}$.

In Brazil, studies on the nurse's work environment in the health services remain at an early stage. Existing studies are concentrated in the Southeast region and focus on the scenario of Intensive Therapy Units $^{(3-5)}$. As a result, further studies exploring the characteristics of the nurse's professional work environment in different scenarios are important. It is worth emphasizing that environments with characteristics that favor the nurse's work are directly related to the quality of the care and to professional satisfaction ${ }^{(5-6)}$.

Specifically in relation to the work of nurses in the emergency services, emphasis is placed on the need for a constant striving for the development of strategies for overcoming the challenges posed to the work in an environment characterized by the constant demand for attendance ${ }^{(7)}$. These services are inserted in the political and structural scenario of the Unified Health System and of the National Emergency Care Policy, which establish attendance to seriously-ill cases requiring immediate attendance as the objecti$\mathrm{ve}^{(7-8)}$.

In spite of the advances in the implementation of policies decentralizing attendance in cases of urgent/emergency care, the hospital services continue to be the places where there is greatest demand for emergency attendance, and to be the gateway to the health system, even when the case is not characterized as emergency from the clinical point of view ${ }^{(7-8)}$. This extensive demand for attendance results in the overcrowding of these services, which compromises the quality of the care provided to the patients and overloads the health professionals ${ }^{(9)}$.

The increase in demand for attendance in the emergency services is related to the number of accidents and cases of urban violence. In Brazil, external causes are the third greatest cause of death, and the fifth cause of hospitalization in the Unified Health System ${ }^{(9)}$. In addition to this, the population's greater life expectancy, and the increase in morbidity and mortality from cerebrovascular and coronary diseases has also contributed to the increase in the rates of demand for attendance in these services ${ }^{(10-11)}$.

As a result, in order to contribute to the nurse's practice in the emergency services, and to advance the understanding of the characteristics of the work environment in this sector, this study's guiding question was defined as: What are the characteristics of the work environment of the nurse in a hospital emergency service?

As a theoretical-conceptual framework, we considered the characteristics of the nurse's work environment: autonomy, control over the environment, relationships between physicians and nurses, and organizational support. Autonomy and control over the environment represent the nurse's freedom to resolve problems referent to the quality of the care. The relationships between physicians and nurses involve professional respect and effective communication for constructing integrated care plans. Organizational support relates to the conditions provided by the organization for the nurses' professional practice ${ }^{(3,12)}$.

This study's aim was to analyze the characteristics of the nurse's work environment in a hospital emergency service.

\section{Methods}

A mixed methods study, with a concurrent triangulation strategy, in which quantitative and qualitative data are collected simultaneously with a view to integrating information at the point of the results' analysis ${ }^{(13)}$. 
The study scenario was the emergency service of a teaching hospital in the South region of Brazil, which provides attendance free at the point of use for adult patients. It is organized in five areas of attendance: embracement with triage, observation room, minor surgery room, inpatient beds and resuscitation room.

Data collection was undertaken between October 2012 and March 2013, by undergraduate and postgraduate students in nursing, under the researchers' supervision.

The quantitative study was of the descriptive-exploratory type. The target-population was made up of 19 of the 21 nurses in the department, who met the eligibility criteria: inclusion (exercising care activities and to have a minimum length of experience of three months) and exclusion (absence due to holidays or leave of any type). All 19 nurses answered the instrument and were, therefore, the study participants.

In the collection of the quantitative data, a form for personal and professional characterization was used, along with the Brazilian version of the Nursing Work Index - Revised (B-NWI-R). The B-NWI-R was validated for use in Brazil and enables one to measure characteristics of the work environment which favor the nurse's practice. It is made up of the following subscales: autonomy (five items), relationship between physicians and nurses (three items), control over the environment (seven items) and organizational support (10 items derived from the previous subscales) $)^{(3,12)}$.

The B-NWI-R's measurement scale is of the Likert type, and its score varies between one and four points. The participant states whether they agree or not with the statement "this fact is present in my daily work", using the options: (1) completely agree; (2) partly agree; (3) partly disagree and (4) completely disagree. The lower the score, the greater the presence of characteristics which favor the nurse's practice, it being the case that values below 2.5 represent environments which favor professional practice ${ }^{(3,5)}$.

The data were tabulated using Microsoft Ex- cel ${ }^{\circledR}$ and were analyzed using the Statistical Package for the Social Sciences program. Descriptive statistics were used, with calculation of absolute frequency (n) and percentages (\%) for categorical variables, and measurements of position and dispersion (mean, median, standard deviation, and minimum and maximum values) for the continuous variables. The reliability of the B-NWI-R was evaluated using the Cronbach Alpha coefficient, the value of which was 0.830 .

The qualitative research was based in the constructivist approach of Grounded Theory ${ }^{(14)}$. A total of 21 participants were included, with relevant experience in the phenomenon investigated, and were divided into three sample groups constituted over the course of the study, as shown in Figure 1. The data were collected through intensive interviews ${ }^{(14)}$, held individually in the participants' workplace.

\begin{tabular}{|l|l|}
\hline Sample Group = Participants & Objective and focus of the interviews \\
\hline $\begin{array}{l}\text { Sample Group 1 = Nine nurses } \\
\text { from the Emergency Service }\end{array}$ & $\begin{array}{l}\text { To investigate the characteristics of the } \\
\text { work environment in the emergency } \\
\text { service, based on the nurses' } \\
\text { experiences. }\end{array}$ \\
\hline $\begin{array}{l}\text { Sample Group 2 } \\
\text { professionals from the health } \\
\text { team (two physicians and four } \\
\text { nurse technicians) }\end{array}$ & $\begin{array}{l}\text { To explore aspects referent to the } \\
\text { with the health team. }\end{array}$ \\
\hline $\begin{array}{l}\text { Sample Group 3 Six nurse } \\
\text { managers of the institution }\end{array}$ & $\begin{array}{l}\text { To explore aspects related to the } \\
\text { organizational support for the nurses' } \\
\text { practice. }\end{array}$ \\
\hline
\end{tabular}

Figure 1 - The study's sample groups

The interviews were recorded on an audio device and lasted an average of 20 minutes. The recordings were transcribed and inserted into the NVIVO ${ }^{\circledR}$ software for the organization of the data. The data analysis took place through an initial phase with the denomination of each data segment, followed by a focused phase, in which more significant or frequent initial codes were classified, integrated, summarized and organized into categories and subcategories ${ }^{(14)}$.

The study complied with the formal requirements contained in the national and international standards regulating research involving human beings. 


\section{Results}

The 19 nurses participating in the quantitative study had a mean age of 34 years old $(\mathrm{min}=24$ years old and max $=49$ years old) and most $(89.0 \%)$ were female. In relation to professional training, 9 (47.3\%) had undertaken a stricto sensu postgraduate specialization course and 7 (36.8\%), a lato sensu specialization course. Length of experience as a nurse varied between seven months and 28 years, the minimum length of service in the unit being seven months, and the maximum -13 years.

The nurses' work environment was shown to be favorable, according to the mean of the B-NWI-R. In relation to the B-NWI-R's subscales, it was observed that the nurses have autonomy, good relationships with the physicians, and organizational support. However, the control over the environment was evidenced as unfavorable. Table 1 presents the values obtained for the characteristics of the nurses' work environment in the emergency department.
Based on the qualitative study, the following category is presented: "Seeking to organize the work environment for demand which exceeds attendance capacity", which is made up of four subcategories described below: 1) Achieving professional autonomy based on professional experience; 2) Losing control over the work environment; 3) Establishing good professional relationships with the physicians; and, 4) Being able to rely on the support of the nurse management.

\section{Achieving professional autonomy based on pro- fessional experience}

The nurses' autonomy in the emergency service is related to their experience acquired over the course of their exercising of their profession and the search for scientific knowledge. Furthermore, the support of work colleagues and the influence of other professionals held as examples were fundamental for achieving the security and tranquility necessary for working in

Table 1 - The work environment of the emergency department, according to the B-NWI-R. ( $n=19)$

\begin{tabular}{|c|c|c|}
\hline Characteristics & AM* & SD** \\
\hline Autonomy & 2.05 & 0.40 \\
\hline (A) A supervisory staff that is supportive of nurses & 2.47 & 0.77 \\
\hline (B) Nursing controls its own practice & 1.89 & 0.65 \\
\hline (C) Freedom to make important patient care and work decisions & 1.84 & 0.50 \\
\hline (D) Not being placed in a position of having to do things that are against my nursing judgment & 1.84 & 0.76 \\
\hline (E) A nurse manager backs up the nursing staff in decision making, even if the conflict is with a physician & 1.84 & 0.68 \\
\hline Control over the environment & 2.63 & 0.43 \\
\hline (F) Adequate support services allow me to spend time with my patients & 2.79 & 0.91 \\
\hline (G) Enough time and opportunity to discuss patient care problems with other nurses & 2.74 & 0.93 \\
\hline$(\mathrm{H})$ Enough registered nurses on staff to provide quality patient care & 2.26 & 0.99 \\
\hline (I) A nurse manager who is a good manager and leader & 1.84 & 0.50 \\
\hline (J) Patient assignments foster continuity of care (i.e., the same nurse cares for the patient from one day to the next) & 2.95 & 0.78 \\
\hline (K) Enough staff to get the work done & 2.79 & 0.85 \\
\hline (L) Opportunity to work on a highly specialized unit & 2.47 & 0.79 \\
\hline Relationships between physicians and nurses & 2.33 & 0.40 \\
\hline (M) Physicians and nurses have good working relationships & 2.00 & 0.47 \\
\hline (N) Much teamwork between nurses and doctors & 2.26 & 0.80 \\
\hline (0) Collaboration (joint practice) between nurses and physicians & 2.35 & 0.58 \\
\hline Organizational support*** & 2.35 & 0.34 \\
\hline Total: B-NWI-R & 2.32 & 0.29 \\
\hline
\end{tabular}


the department. The nurses here have a fair bit of autonomy (E2). ... My autonomy came from a number of things, with experience, study and the other professionals who are with me. For sure, we always end up reflecting people whom we admire. The security itself comes with experience, observing people who we look up to, when I first came it was really difficult... I felt like quitting, and at high speed... But with time and the support of the team, and because of everything that one learns, nowadays I feel relaxed (E6).

One of the participants emphasized the autonomy relating to the nurse's work, as the work in an emergency situation depends on the team, in which each professional is responsible for a part of the work. I think I have good autonomy... I believe that we depend on the team, but in a general way, I believe that I have autonomy when I carry out my work (E8).

\section{Losing control over the work environment}

The lack of structural conditions for the attendance by the emergency service was evidenced by the insufficient number of beds and gurneys in relation to the demand for attendance, which compromises the nurses' control over the environment. Nonetheless, resolving these problems goes beyond the nurses' governance, as these problems are related to the hospital's structure and to the organizational characteristics themselves of the urgent care network. The lack of structure leads to overcrowding, which impairs the nurse's work and limits her control over the professional practice environment. I think that the lack of space for the patients is beyond our control ... There are too many people coming to the emergency department, the number of beds and gurneys is limited. The demand is greater than the space which we can offer... I believe that my work is affected, actually, I lose control over my practice (E5). Sometimes, we have the feeling that we are unable to keep up when we are on duty, you get the feeling that "my God, 1001 things are happening and I can't keep up with them"... (E7) ... it is all too ungoverned, and the nurse cannot have control of everything which happens (E18).

Another unfavorable aspect was the insufficient number of professionals in the department, taking into account the existing demand for work. Associa- ted with this, the rates of absenteeism cause a work overload for the nursing team in the unit. The lack of staff also limits us quite a lot, that question of people off on sick leave which, sometimes, we cannot cover, this impairs things quite a lot because it overloads those who are working (E6).... We have to cover not only the nurses' rota but also the nurse technicians as well, and when we cannot cover the nurse technicians' rota with nurse technicians, we take their place. (E7). What disappoints me a little is, I think, is this backup - which we don't have (E15).

\section{Establishing good professional relationships with the physicians}

The professional relationship between nurses and physicians was classified as good, as it is characterized by cordiality and constant communication/ interaction. The nurses feel recognized by the medical team, and perceive themselves as a reference for the health team regarding issues relevant both to the work environment and to the patient care. The doctors ask us what they can do, it is an interaction that we have with the entire team, whether medical, physiotherapy, psychology or the social services (E3). We can sit down, debate things, discuss things ,... The physicians respect us and listen (E7). The physicians report on what they are doing, and communicate things to me - there is this interaction... (E8).

The individual behaviors of some professionals, such as lack of manners or bad moods, were scored as difficulties for a harmonious working relationship. One nurse also mentioned communication difficulties regarding conduct by physicians which negatively influences the nursing work, such as admitting patients. ... It happens that the physician attends the patient and sends the patient from the consulting office to be admitted on the ward and doesn't tell the nurse ... (E4).... Of course there is always one physician who you pray will not be on duty on your shift, because the person is either not there or was extremely rude, and nobody likes having to put up with somebody in a bad mood on a daily basis, especially at work (E11).

\section{Being able to rely on the support of the nurse ma- nagement}

The study participants emphasized the au- 
tonomy and openness to dialogue on the part of the nurse management as being an attitude which favors the work environment in emergency care. The team meetings, and communication by email, favor access to information and allow collective participation in the decision-making processes. We can walk up to our immediate managers and talk with them directly, because they are here all day and if you need something from outside, they make contact or intermediate (E2).... There is the autonomy for this as well, and the freedom to talk with the management (E7).... We have meetings every two months. Everything is discussed and decided at these meetings, and afterwards a memo is forwarded to the nurses by email (E19).

Figure 2 illustrates the articulation between the quantitative and qualitative results.

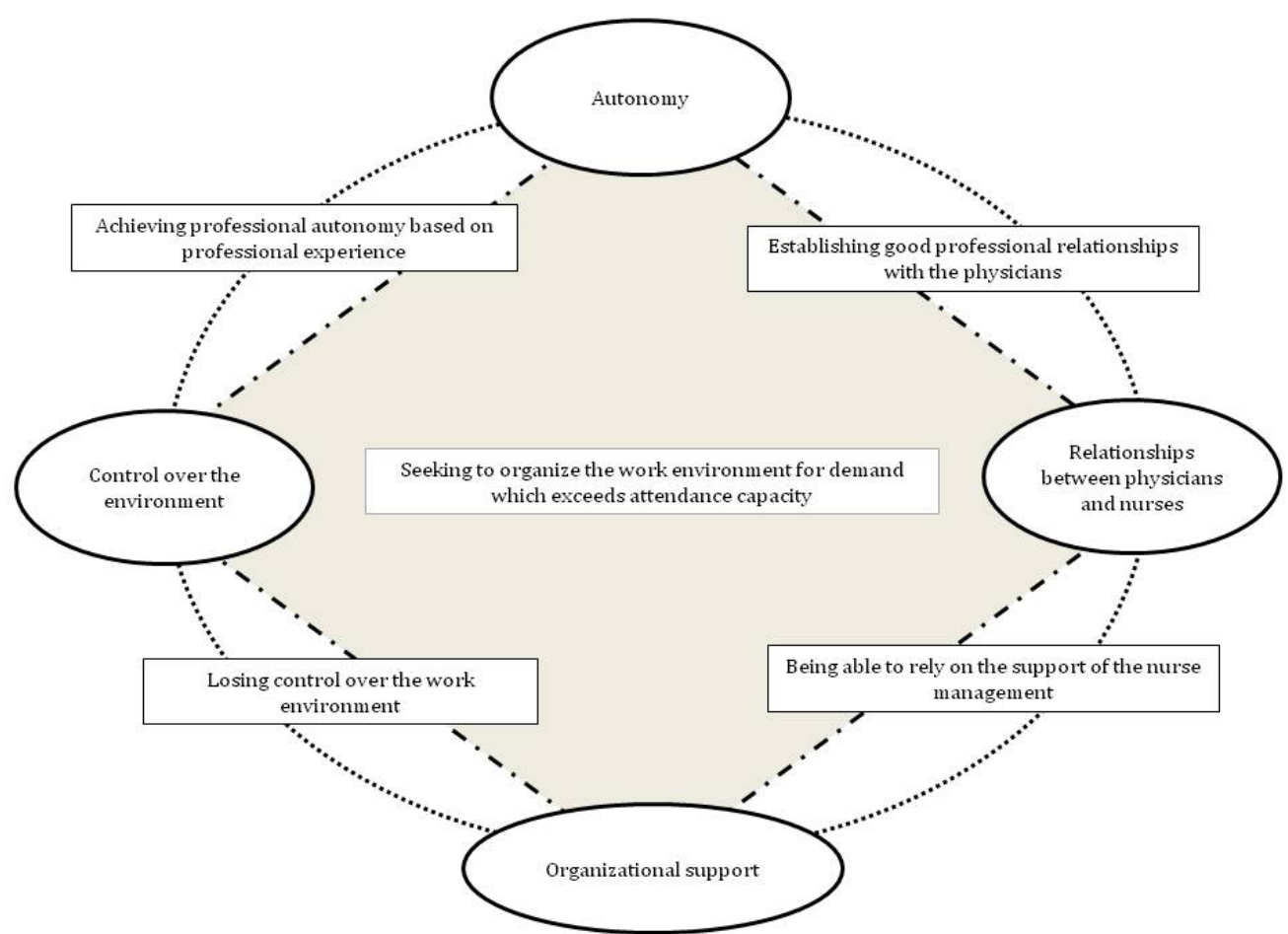

Figure 2 - Diagram representing the articulation between the quantitative and qualitative results

\section{Discussion}

This study's limitations are related to the quantitative sample, which was small $(\mathrm{n}=19)$ and limited to a single hospital emergency service. As a result, emphasis is placed on the relevance of undertaking further studies with a larger number of participants and in other scenarios, so as to obtain a broader understanding of the issue in question.

In the quantitative study, the mean total of the B-NWI-R was similar to the values described by previous Brazilian studies which used the same instrument in the context of intensive care units in São Pau$\mathrm{lo}^{(4,5)}$. However, differences were evidenced in relation to the scores of the subscales 'autonomy' and 'control over the environment'. 'Autonomy' was the characteristic which was most favorable, while 'control over the environment' was shown to be unfavorable in the context investigated.

In the qualitative study, the nurses' perspective regarding autonomy aligns with the favorable mean of this subscale of the B-NWI-R. The nurses' autonomy is associated with expertise and know-how developed throughout their professional experience. One should also highlight the personal dedication of the nurses in their search for professional qualification and improvement. In this way, it is reinforced that autonomy is knowledge acquired through the practical experiences, and that it ensures the routine exercising of the 
profession $^{(15)}$.

The characteristics of the work in the emergency area themselves can also contribute to greater independence in the nurses' actions. The care of patients in the emergency service requires the professionals to undertake immediate actions and interventions which, often, are stipulated in protocols and/or institutional norms and routines. This promotes more autonomous work on the part of these nurses in comparison with other hospital scenarios.

In this regard, one study with nurses in the Emergency Department of a public hospital in the state of Paraná, Brazil, evidenced that embracement with assessment and risk classification, under an organizational protocol, favors the nurse's autonomy and allows the nurse greater responsibilization with the service users ${ }^{(16)}$. Moreover, it is worth mentioning that independence of thought and action in the work, through intellectual autonomy and creativity, are directly related to motivation in the work ${ }^{(17)}$.

The quantitative and qualitative results also converged upon the unfavorable characteristics of the nurses' control over the work environment in the emergency service. The nurses' main difficulties are related to overcrowding, the lack of resources, and the insufficient number of professionals to undertake the work, which compromises the service's capacity to care and the continuity of the care.

These difficulties relate to the care profile and to the characteristics of the emergency services in Brazil, which, as units, are open 24 hours a day and face a constant demand to provide attendance. Under these circumstances, the work is a challenge for the nurses, who are responsible for managing the care for the patients in these scenarios, which includes ensuring the planning, undertaking estimates, and the provision of the necessary resources for providing the care and organizing the service ${ }^{(7,16)}$. The limitations posed by the resources available and the working conditions which are inappropriate for the attendance can cause demotivation and physical and psychic overloading for the staff. Moreover, they can directly and negative- ly influence the quality of the service provided. As a result, investing in improvements in these conditions represents - without any doubt - an important step towards making it possible for the professionals to take satisfaction in the work, as well as improving the quality of the care in the emergency service ${ }^{(16-17)}$.

One of the most frequent results of this work overload is that the professionals become ill, which results in high rates of absenteeism and staff on sick leave, entailing direct consequences for the organization of the service and the quality of the care. Professional dissatisfaction was also raised as a condition for the high rate of sick leave, which has a considerable negative influence on the control over the environment ${ }^{(17)}$.

Regarding the relationships between physicians and nurses, this subscale obtained a favorable mean in the quantitative study, which aligned with the findings of the qualitative study. One North American study evidenced that good relationships between physicians and nurses contribute to greater satisfaction with the work among the professionals and also favor the organization of the care environment in the emergency service ${ }^{(18)}$.

In spite of the positive mean of the subscale 'relationship between physicians and nurses', in the quantitative results, item " $M$ - The physicians and nurses have good working relationships" ( $\mathrm{AM}=2.00$; $\mathrm{SD}=0.47)$ presented a more favorable mean than did the item "O - Collaboration (joint practice) between nurses and physicians" ( $\mathrm{AM}=2.35 ; \mathrm{SD}=0.58)$. This difference may indicate the existence of work relationships between physicians and nurses which, although good, do not always correspond to teamwork and/or collaborative work.

For teamwork to be considered interprofessional and collaborative, it is necessary for there to be communication, interaction, recognition of professional roles, articulation of actions, trust and the establishment of common care objectives between the staff. Collaboration between the health professionals is fundamental for quality healthcare, safety, and the satisfaction of patients and professionals ${ }^{(19)}$. 
Regarding organizational support, the participants emphasized the importance of the support from, and communication with, the nurse management. The work of the nurse manager as a leader is important for identifying obstacles in the work and establishing organizational objectives to be achieved by the nursing team ${ }^{(20)}$.

\section{Conclusion}

Based on this study, it was observed that the characteristics of the work environment in the emergency department, assessed through the B-NWI-R in the quantitative study, favor the nurse's practice, with the exception of control over the environment. The qualitative results showed that autonomy arises from the nurses' personal effort and development, establishing good professional relationships with physicians, and being able to rely on the support of the nurse managers of the service and institution. The difficulties regarding control over the environment are related to overcrowding and the lack of resources and of professionals, which characterize the work in the emergency area and hinder the undertaking of the care activities.

\section{Collaborations}

Santos JLG, Menegon FHA, De Pin SB, Erdmann $\mathrm{AL}$, Oliveira JTO and Costa IAP contributed to the analysis and interpretation of the data, editing of the manuscript, relevant critical revision of the intellectual content and final approval of the version for publication.

\section{References}

1. Numminen O, Ruoppa E, Leino-Kilpi H, Isoaho $\mathrm{H}$, Hupli M, Meretoja R. Practice environment and its association with professional competence and work-related factors: perception of newly graduated nurses. J Nurs Manag. 2016; 24(1):111.
2. Erickson IJ, Duffy M. Psychometric evaluation of the Revised Professional Practice Environment (RPPE) scale. J Nurs Adm. 2009; 39(5):23643.

3. Gasparino RC, Guirardello EB, Aiken LH. Validation of the Brazilian version of the Nursing Work Index-Revised (B-NWI-R). J Clin Nurs. 2011; 20(23-240:3494-501.

4. Balsanelli AP, Cunha ICK. The work environment in public and private intensive care units. Acta Paul Enferm. 2013; 26(6):561-8.

5. Panunto MR, Guirardello EB. Professional nursing practice: environment and emotional exhaustion among intensive care nurses. Rev Latino-Am Enfermagem. 2013; 21(3):765-72.

6. Aiken LH, Sloane DM, Bruyneel L, Heede KV, Griffiths P, Busse R, et al. Nurse staffing and education and hospital mortality in nine European countries: a retrospective observational study. Lancet. 2014; 383(9931):1824-30.

7. Santos JLG, Lima MADS, Pestana AL, Garlet ER, Erdmann AL. Challenges for the management of emergency care from the perspective of nurses. Acta Paul Enferm. 2013; 26(2):136-43.

8. Silva DS, Bernardes A, Gabriel CS, Rocha FLR, Caldana G. A liderança do enfermeiro no contexto dos serviços de urgência e emergência. Rev Eletr Enf [Internet]. 2014 [citado $2017 \mathrm{dez}$ 13]; 16(1):211-9. Disponível em: https://www.fen.ufg. br/fen_revista/v16/n1/pdf/v16n1a24.pdf

9. Campos MR, Doellinger VR, Mendes LVP, Costa MFS, Pimentel TG, Schramm JMA. Morbidity and mortality associated with injuries: results of the Global Burden of Disease study in Brazil, 2008. Cad Saúde Pública. 2015; 31(1):121-36.

10. Manges CA. Shared governance and work engagement in the emergency nurses: reality or perception. J Emerg Nurs. 2016; 42(6):469-70.

11. Mendes AS, Reis VRSS, Menezes TMO, Santos CAST, Mussi FC. Access of patients with myocardial infarction to cardiology reference hospitals. Acta Paul Enferm. 2014; 27(6):505-12.

12. Gasparino RC, Guirardello EB. Translation and cross-cultural adaptation of the "Nursing Work Index - Revised" into Brazilian Portuguese. Acta Paul Enferm. 2009; 22(3):281-7. 
13. Fetters MD, Curry LA, Creswell JW. Achieving integration in mixed methods designs - principles and practices. Health Serv Res. 2013; 48(6):213456.

14. Charmaz, K. A construção da teoria fundamentada: guia prático para análise qualitativa. Porto Alegre (RS): Artmed; 2009.

15. Bellaguarda MLR, Padilha MI, Pereira Neto AF, Pires D, Peres MAA. Reflexão sobre a legitimidade da autonomia da enfermagem no campo das profissões de saúde à luz das ideias de Eliot Freidson. Esc Anna Nery. 2013; 17(2):369-74.

16. Sakai AM, Rossaneis MA, Haddad MCFL, Sardinha DSS. Feelings of nurses in the reception and risk classification evaluation in the emergency room. Rev Rene. 2016; 17 (2):233-41.

17. Mendes ACG, Araújo Júnior JLAC, Furtado ASM, Duarte PO, Silva ALA, Miranda GMD. Condições e motivações para o trabalho de enfermeiros e médicos em serviços de emergência de alta complexidade. Rev Bras Enferm. 2013; 66(2):161-6.
18. Ajeigbe DO, McNeese-Smith D, Phillips LR, Leach LS. Effect of nurse-physician teamwork in the emergency department nurse and physician perception of jobsatisfaction.J Nurs Care [Internet]. 2014 [cited 2016 Dec 13];3:141. Available from: h t t p s : / / w w w.n c bi .n l m.nih.gov / pubmed/23425911

19. Souza GC, Peduzzi M, Silva JAM, Carvalho BG. Teamwork in nursing: restricted to nursing professionals or an interprofessional collaboration? Rev Esc Enferm USP. 2016; 50(4):642-9.

20. Llapa-Rodriguez EO, Oliveira JKA, Lopes Neto D, Campos MPA. Nurses leadership evaluation by nursing aides and technicians according to the 360-degree feedback method. Rev Gaúcha Enferm. 2015; 36(4):29-36. 